\title{
SUICÍDIO COMO PAUTA POPULAR (OU O SENSACIONALISMO COMO RESISTÊNCIA)
}

\author{
Milena Carvalho Bezerra Freire de Oliveira-Cruz ${ }^{1}$
}

\begin{abstract}
Resumo: Este artigo parte da perspectiva da construção do suicídio enquanto um tabu, sendo por isso tema normalmente abolido das pautas jornalísticas dentro de uma ordem hegemônica, que propõe a racionalidade e a objetividade dos temas expostos. Neste contexto, a reflexão volta-se para a constante cobertura de casos de suicídio na imprensa do estado do Amapá, associando esta narrativa aos conceitos de popular e de sensacionalismo. Assim, a partir da noção de sensacionalismo como processo cultural, constituído através de fluxos do imaginário que relacionam representações e mediações (ENNE, 2007), propõe-se mapear o processo histórico e as matrizes culturais que compõem a inscrição da morte voluntária nos meios massivos amapaenses para melhor observar o sentido que o tema adquire neste contexto cultural específico.
\end{abstract}

Palavras-chave: Suicídio. Sensacionalismo. Cultura popular.

\begin{abstract}
This article takes the perspective of the construction of suicide as a taboo subject, being for this reason a subject normally abolished in media coverage within a hegemonic order, which proposes the rationality and objectivity of the subjects exposed. In this context, the discussion analyses the constant coverage of suicide cases in the press of Amapa, linking this narrative to the concepts of popular and sensationalism. Thus, from the notion of sensationalism as a cultural process, constituted by flows of imagery relating representations and mediations (ENNE, 2007), we propose to map the historical process and cultural matrices that compose the inclusion of voluntary death in Amapá mass media to better observe the effect that this subject acquires in this specific context.
\end{abstract}

Key-words: Suicide. Sensationalism. Popular culture

\section{Introdução}

A construção que orienta a significação do homem se funda em dois conceitos importantes que são base neste ensaio: a sua existência enquanto ser de cultura e a consciência de sua condição como ser mortal, finito. Para Morin (1997: 10-11), a reprodução dos sistemas simbólicos que compõem a cultura só tem sentido pleno em função da morte, o que faz afirmar que sociedade só se institui como organização por, com e na morte. É pela certeza do fim da vida, também, que se constituem uma série de representações que dão parâmetros para

\footnotetext{
${ }^{1}$ Professora do Departamento de Ciências da Comunicação da Universidade Federal de Santa Maria. Email: milena.freire@terra.com.br
} 
as ações, noções de moral (em âmbitos individuais e coletivos) sobre possibilidades, objetivos e papéis que dão conta do aproveitamento do tempo finito a ser vivido.

Nestes termos, tomando a morte como um signo fundamental, mas não o único, entende-se como as construções simbólicas oriundas da cultura permeiam a compreensão do homem sobre si e orientam sua conduta conforme as representações partilhadas no seu grupo. Logo, vê-se que a cultura abrange processos sociais de significação que incluem a produção, a circulação e o consumo de signos na vida social. Portanto, a coordenação do funcionamento e a designação de sentido às práticas sociais são constituições preponderantemente culturais (CANCLINI, 1997a: 40-41). A noção de cultura assume, assim, o espaço da reprodução social e organização das diferenças, considerando a multiplicidade de signos, sujeitos e práticas que, também, se constroem, interagem e se transformam mutuamente e constantemente.

A comunicação, desta feita, situa-se em lugar substancial pelo papel que "desempenha na estrutura do processo cultural, pois as culturas vivem enquanto se comunicam umas com as outras e esse comunicar-se comporta um denso e arriscado intercâmbio de símbolos e sentidos" (MARTIN-BARBERO, 2003: 68). Fica claro, portanto, de que maneira o olhar sobre a comunicação permite um entendimento sobre as práticas e significações que compõem a cultura. Uma vez se tratando de representações que situam o entendimento que o homem tem de si e da coletividade, como acontece com as significações procedentes do "saber" da morte, temos a aproximação de dois elementos fundantes do que aqui se propõe como objeto de reflexão: as notícias sobre suicídio.

Considerado a ordem consensual (logo, hegemônica) que trata o tema como tabu, e, por isso, como tema impróprio para pauta nos jornais de referência, a perspectiva deste texto volta-se para a observação da constante cobertura de casos de suicídio na imprensa do estado do Amapá. Assim, a partir da noção de sensacionalismo como processo cultural, constituído através de fluxos do imaginário que relacionam representações e mediações (ENNE, 2007), pretende-se mapear o processo histórico e as matrizes culturais que compõem a inscrição da morte voluntária nos meios massivos amapaenses para melhor observar o sentido que o tema adquire neste contexto cultural específico.

\section{Entre pautas e estatísticas: observando e tensionando os dados}

Tido como problema de saúde pública e, por isso, supervisionado por instâncias governamentais e sociais em todo o mundo, o suicídio registrou no Brasil uma taxa média de 
4,6 óbitos para cada 100mil habitantes em 2006, conforme última atualização disponível pelo Ministério da Saúde, publicada no relatório "Indicadores e Dados Básicos" do ano de 2008 $\left(\mathrm{MS}, 2008^{2}\right)$.

Em comparação aos critérios internacionais da Organização Mundial de Saúde $\mathrm{OMS}^{3}$, os índices nacionais são considerados baixos. Mas, em função de sua população expressiva, o Brasil se encontra entre os 10 países com maiores números absolutos de suicídio (8.639 em 2006). Além disso, são consideráveis os registros evolutivos de taxas em algumas localidades específicas, como o estado do Amapá, que entre os anos de 1993 e 2002 teve um aumento de 218,2\% no número total de casos (WAISELFISZ, 2005: 112).

O ambiente social em que se pretende construir esta reflexão é, portanto, Macapá, capital do estado do Amapá. Em dados divulgados em 2004, a cidade foi apontada como capital $^{4}$ com maior índice de suicídios masculinos ${ }^{5}$ no país, com uma taxa de 13,6 óbitos/ 100.000 homens. A definição desta localidade para a pesquisa, além do que fica explícito pelas estatísticas de óbitos por suicídio, se dá pela exposição freqüente de mortes voluntárias nas pautas da imprensa local, nos mais diversos veículos: TV, rádio, impressos e Internet. Esta inscrição do suicídio na narrativa jornalística em Macapá aparece, a princípio, como contraponto à expectativa apontada por Arthur Dapieve (2007: 20), em que "a imprensa se colocaria não como vetor do 'contágio', mas como instância social solidária ao tabu que a suplanta".

Nesta perspectiva, Dapieve afirma que a imprensa, influenciada pela idéia de contágio $^{6}$ (que incentivaria outros suicídios a partir da divulgação destes casos), reserva ao suicídio um tratamento discreto e superficial, sustentando o lugar de tabu social que o tema ocupa. Diz ainda, que, quando há a cobertura jornalística justificada pelo "valor-notícia" que se agrega àquela morte, são casos isolados, e, preferencialmente, distantes da realidade do leitor.

\footnotetext{
2 Ministério da Saúde (2008). Relatório "Indicadores e Dados Básicos" - Taxa de mortalidade causas externas/suicídio, ano 2006. Disponível em http://tabnet.datasus.gov.br/cgi/deftohtm.exe?idb2008/c09.def 3 Classificam a mortalidade por suicídio como baixas, quando os coeficientes são menores que 5ób/100mil hab; média para coeficientes entre cinco e menos de 15 ób/100mil hab; alta, quando são entre 15 e menos de 30ób/100mil hab e muito alta, quando os coeficientes são de 30ób/100mil hab ou maiores.

${ }^{4}$ Há de se considerar, nestes dados, que a região metropolitana Macapá concentra $74,48 \%$ da população do estado do Amapá. (IBGE, contagem da população mais recente, realizada em 2007. Publicado no DOU de 05/10/2007).

${ }^{5}$ A taxa de suicídios masculinos é considerada preponderante no país, pois corresponde, em média do ano de 2002, a 78\% do coeficiente total (WAISELFISZ, 2005: 129).

${ }^{6} \mathrm{O}$ pensamento de Dapieve concorda com as regras presentes nos manuais de redação que, normalmente, sugerem que se evite a cobertura de casos de suicídio. Da mesma forma, a Organização Mundial de Saúde, demonstra preocupação com o tratamento dado ao suicídio pelos jornais quando disponibilizou, em 2000, um guia aos profissionais da imprensa orientando sobre cuidados necessários no tratamento deste tema (Disponível em www.who.int/ina-nqo/nqo/nqo027.htm - Associação Internacional para Prevenção do Suicídio - IASP).
} 
No estudo de Dapieve, que se dedicou à análise da cobertura jornalística sobre suicídio no jornal O Globo no ano de 2004, das 142 matérias que tratavam (ou apenas citavam) o suicídio, apenas 39 se referiam a mortes daquele ano. Destas, 29 abordavam mortes de suicidas em atentados terroristas. As 10 restantes incluíam um suicídio em grupo de jovens japoneses e três, por fim, tratavam de suicídios ocorridos no estado do Rio de Janeiro. Uma destas três, apenas, na capital do Estado - divulgada, de acordo com o jornalista, em função da proeminência do falecido. Segundo Dapieve (2007: 116 e 119), dos 96 casos registrados na capital naquele ano, apenas um foi pauta d'O Globo.

Numa comparação breve com a cobertura jornalística sobre o suicídio em Macapá em período semelhante, em levantamento realizado durante os anos de 2004 e 2005 em um dos principais jornais da cidade, "A Gazeta", foram noticiados 43\% e 61\% dos suicídios registrados pela Polícia Técnica do Amapá, respectivamente, nestes dois anos. Embora esta não seja uma proposta de análise quantitativa, fica claro porque o contexto macapaense se diferencia. Isso, ressalte-se, é parte de uma prática que abrange os veículos de uma maneira geral, colocando as pautas sobre suicídio ao lado de assuntos como política, economia ou esportes. Os dados sobre o jornal amapaense foram catalogados em um projeto de iniciação científica que coordenei com o intuito de inventariar e analisar as notícias sobre suicídio veiculadas naquele espaço.

O estudo pautou-se prioritariamente na análise dos textos jornalísticos e no mapeamento de indicadores sociais que, segundo pesquisas sobre o tema, corroboram como causas externas para o ato suicida. Como resultados, foram apontadas a superficialidade no tratamento do tema e a repetição literal dos textos que, carregados de artifícios dramáticos (através de imagens e narrativas emocionais), mantinham o enredo e apenas atualizavam o nome do suicida e o cenário da morte. No estudo, foi registrada ainda a contabilização dos casos de suicídio como um recurso recorrente nestas narrativas, o que terminava por enfatizar a "liderança" do Amapá no ranking nacional de mortes voluntárias.

As estatísticas sobre os casos de suicídio têm mostrado números alarmantes no Estado. Só ano passado, 44 pessoas morreram vítima de suicídio, dos quais 28 aconteceram na Capital. Os números mostram que, em média, aconteceu um suicídio a cada oito dias.

Em 2005 essa média de incidência está ainda mais assustadora. Até ontem (1), nove pessoas haviam tirado a própria vida, isso significa uma média de, aproximadamente, uma vítima a cada 3,6 dias, ou seja, a incidência aumentou quase três vezes em relação a $2004 .^{7}$

\footnotetext{
${ }^{7}$ Trecho de matéria intitulada "Homem é encontrado enforcado no Jardim I", publicada no periódico A Gazeta em 02.02.2005.
} 
Em menos de uma semana 2 suicídios foram registrados no Amapá, que possui a segunda maior média de casos desta natureza em toda América Latina. $^{8}$

Tais recursos, observados nas matérias catalogadas na pesquisa, referem-se diretamente àquilo que Pedroso (apud AMARAL 2005: 5) vai caracterizar no jornalismo sensacionalista: a intensificação, o exagero; a valorização da emoção em detrimento da informação; a exploração do extraordinário e do vulgar; a produção discursiva na perspectiva trágica, violenta, insólita, grotesca ou fantástica.

Quanto aos indicadores sociais, foram levantados na pesquisa dados que demonstravam o frágil desenvolvimento econômico e social daquele estado em contraponto a um grande fluxo migratório - o que interferiria, respectivamente, na precariedade das condições de vida e na fragilidade dos vínculos de pertencimento.

Embora os indicadores sociais e a freqüência do tema na mídia local não tenham mudado (no ano seguinte ao estudo - 2006 - mais de 50\% dos casos foram tratados pelo mesmo periódico), os registros de suicídio no Amapá tiveram uma sensível mudança. Em termos nacionais, o índice das mortes voluntárias entre homens caiu de $1^{\circ}$ para $11^{\circ}$ no país, em dois anos ${ }^{9}$.

Em contrapartida, se tomarmos como base Porto Alegre, a capital de estado que ocupa o primeiro lugar em estatística de suicídios masculinos no país no ano de 2006 (com 13,8 óbitos por 100 mil habitantes), percebemos que neste contexto cultural vale a prerrogativa cautelosa da imprensa, que não cobre, ou evita pautar, casos de suicídios.

Temos, assim, dois posicionamentos distintos sobre a atuação da imprensa no tratamento do suicídio, sendo um de âmbito geral (ou mais abrangente) que suaviza ou evita o tema; e o outro em contexto mais específico que aborda, nomeia, descreve e apresenta os óbitos. Além dos modos distintos de tratar o suicídio na imprensa, temos ainda, como dado para refletir, a oscilação dos índices de mortes voluntárias. O que sugere a impossibilidade de tratar deste objeto investigando apenas o texto ou buscando relação direta entre óbitos e a explicitação (ou não) dos casos na mídia.

A proposta deste texto, então, centra-se na construção de um "modo de ver" este cenário, em uma reflexão que transpassa o tema em si e procura privilegiar seu caráter processual (imbuído de tensionamentos e negociações), aproximando esta narrativa dos

\footnotetext{
${ }^{8}$ Trecho de matéria intitulada "Mais uma mulher tira a própria vida", publicada no periódico A Gazeta em 28.10.2005

${ }^{9}$ Média de 13,06 óbitos/100 mil habitantes em 2004 e 7,2óbitos/100 mi habitantes em 2006.
} 
conceitos de popular e de sensacionalismo. A valorização da circularidade cultural, portanto, pretende afastar-se da concepção estigmatizada do sensacionalismo enquanto instrumento de alienação, manipulação política e econômica ou resquício cultural do atraso (ENNE, 2007: 13).

É válido ressaltar que os trechos de matérias aqui utilizados como exemplificação da reflexão proposta têm o intuito de contextualizar as matrizes culturais trabalhadas e dar respaldo ao aporte teórico que constitui este ensaio. Não é propósito deste trabalho, portanto, focar-se no texto em si. Este seria objeto de outra análise, ilustrada por um número mais significativo de exemplos - que certamente poderia ser mais aprofundada por especialistas na área de Análise do Discurso.

Fica evidente, então, a intenção de observar a relação entre comunicação e cultura, seus fluxos e articulações, que dão sentido a circulação das notícias sobre suicídio e sua pertinência enquanto pauta em um contexto cultural específico, em detrimento de uma espécie de convenção que retira este tema dos jornais de referência em outros espaços.

Tomando por princípio a sugestão de Stuart Hall (in TRAQUINA, 1993), as notícias se constroem a partir de "mapas de significado" que já constituem a base do conhecimento cultural de uma sociedade, e a interpretação dos acontecimentos derivam de uma perspectiva consensual desta coletividade (valores, interesses e preocupações fundamentais comuns). Nestes termos, se comparada à perspectiva "consensual" mais ampla, o que possibilita que o tratamento do suicídio seja tão diferente na imprensa amapaense? Isto aponta, então, a perspectiva de novos mapas de significado sobre o suicídio, naquele espaço?

Ainda segundo Hall, que afirma ser desta natureza consensual (reproduzida e legitimada no texto jornalístico) uma noção de regularidade que nega quaisquer discrepâncias estruturais importantes, o consenso se apresenta à sociedade como explicações e discursos que articulam o que o público supõe saber sobre a sociedade. Nesta perspectiva, como pensar a construção da realidade, ou esse "saber sobre a sociedade", na cultura amapaense, a partir de circulação das notícias que explicitam o suicídio?

Ao focar como tema para observação a cobertura jornalística sobre o suicídio em Macapá, a relação que pretendo destacar não se volta para a noção do contágio. Não se trata de mensurar a influência da narrativa jornalística no ato suicida, mas de observar a construção de uma narrativa que fala da morte e, sendo este um elemento importante na fundação cultural, fala da própria sociedade. Interessa entender, portanto, neste contexto sócio-cultural específico, a partir da narrativa jornalística, a circulação de valores que compõem o imaginário social sobre o suicídio. 
Desta maneira, a idéia que fundamenta a reflexão aqui proposta entende que a narrativa jornalística, na sua formulação, tanto se apropria das representações que compõem aquela cultura, quanto re-significa a própria construção daquela realidade, quando se insere, também como componente de significação, no contexto social (RESENDE, 2006). Isso se valida na noção de interação entre comunicação e processo social, que concebe os modos de percepção e construção da realidade social num lugar de troca, significação e negociação entre os meios, a sociedade e os indivíduos. Esta noção procura privilegiar a subjetividade conforme propõe Mauro Wilton de Sousa (1994: 33), resgatando-a do espaço que permeia o individual e o social.

\section{Percorrendo o processo histórico: entre o inominável e a manchete}

Para tratar da inscrição do suicídio na narrativa jornalística do Amapá, e conseqüentemente, propor uma reflexão sobre os sentidos provenientes desta relação entre comunicação e cultura, considero importante fazer uma pequena digressão para rever a constituição da morte voluntária como tabu. O que, por conseguinte, permitirá observar melhor a construção da "natureza consensual" que comumente exclui este tema das pautas jornalísticas.

Embora a importância da investigação da morte nas ciências sociais seja incontestável, é possível afirmar que a interdição social que sofre o tema é também refletida na academia, conforme aponta José de Souza Martins (1983: 11): "É preciso negar e contestar o silêncio que pesa sobre este assunto; descobrir ao menos porque a morte é tema interditado e interditado até mesmo para a pequena burguesia acadêmica". Se a cultura é, em si, de natureza comunicativa, as narrativas jornalísticas que (se) apropriam e (se) formulam (d)estas construções simbólicas são objetos igualmente ricos para reflexão. Neste contexto, considerando a morte como questão interditada socialmente, é possível afirmar que a morte voluntária remete o tema a uma condição ainda mais delicada.

$\mathrm{Na}$ filosofia, em particular para os existencialistas, o suicídio é o único problema filosófico verdadeiramente sério. Para Albert Camus, "julgar se a vida merece ou não ser vivida é responder a uma questão fundamental para a filosofia" (CAMUS, s/d: 13). Não adiantam os planos, as realizações, a dedicação, o fim permanece certo - embora posto num lugar escondido, inacessível pela rotina acelerada que oculta artificialmente esta certeza. $\mathrm{O}$ absurdo a que se refere Camus está na consciência da morte, na transformação do mundo nele 
próprio, sem os cenários mascarados pelo hábito ${ }^{10}$. A percepção desta espessura e a estranheza do mundo, e a permanência neste contexto "sem sentido", ainda assim, construída pela esperança "na obtenção deste sentido", é o absurdo por ele concebido.

O lugar da morte voluntária se inscreve nas tramas de intersubjetividade, nas relações, sensibilidades, trocas e apropriações mantidas entre indivíduo e coletividade. Desta forma, o suicídio aparece como uma derivação das significações da morte que ocupa lugar extremamente conflituoso na cultura ocidental. Isso ocorre especialmente porque, se tratando de uma atitude consciente ${ }^{11}$, revela uma desconexão do sujeito com o seu meio, uma fragilidade dos valores que deveriam torná-lo parte inscrita no contexto e no ordenamento social. Além disso, considerando a idéia de sujeito como advinda da própria coletividade, o suicídio consagra o deslocamento do individual e do cívico (MORIN, 1997: 49) porque desnuda a construção simbólica do(s) "sentido(s) da vida", mantidos de forma tão cara pela sociedade ao atribuírem funções e valorações na participação de cada um no alicerce coletivo.

Aqui é importante relembrar a morte como representação da cultura que apresenta noções da regulação social necessárias para organizar as projeções destes "sentidos de vida" individuais - de sujeitos finitos inscritos num coletivo de tempo contínuo (que permanece após sua partida). A participação deste sujeito no social se dá na interiorização dos signos, papéis, e padrões, que variam conforme a experiência, mas que são partilhados e conhecidos por todos - isso torna o mundo subjetivamente real para o sujeito (BERGER e LUCKMANN, 1985: 103). Considerando a compreensão da natureza comunicativa da cultura, percebe-se o papel fundamental da comunicação no processo que produz e faz circular estas significações que se desdobram da certeza da morte e auxiliam constituir os indivíduos (aqui não só decodificadores, mas produtores destes sentidos). Isso, por sua vez, também contribui com as sustentações desta própria coletividade e o seu sentido de realidade.

A partir do fundamento e das conseqüências destas construções, presume-se observar, portanto, alguns dos pilares que sustentam a condenação cívica, religiosa e moral ${ }^{12}$ do suicídio (e sua representação como tabu), como forma de manter distanciada a idéia de

\footnotetext{
${ }^{10}$ Para o filósofo, o suicídio é apenas uma confissão que viver 'não vale a pena', pois mantemos a vida em uma rotina de gestos especialmente por hábito - e decidir morrer implica reconhecer o caráter irrisório deste hábito, o caráter insensato da agitação cotidiana, a inutilidade do sofrimento (CAMUS, s/d: 15).

${ }^{11}$ Como condição fundamental para a conceituação do suicídio, tem-se a intenção do sujeito e a sua informação sobre a conseqüência do ato. Portanto, exige uma representação antecipada da morte - o que inscreve o suicídio como atitude humana, cujas significações variadas são construídas na cultura.

${ }^{12}$ Segundo Dapieve (2007: 66) "Para São Tomás de Aquino, o suicídio era proibido por três razões lógicas e complementares: um atentado contra a natureza e a caridade, pois contradiz a inclinação natural à vida e ao amor-próprio; como um atentado contra a sociedade, porque temos um papel a desempenhar dentro da nossa comunidade; e, por fim, como um atentado contra Deus, proprietário da nossa vida".
} 
desconexão ou liberdade deste sujeito quanto ao fim de sua própria vida - é a sustentação do "todo", especialmente, que se preza. Daí, onde a decisão individual da morte, possibilidade inaceitável, é enquadrada nos campos da anormalidade ${ }^{13}$ (loucura ou possessão) para assumir significação que não revele as "falhas" do projeto social.

Tais "falhas", que incluem tanto o suicídio como outras anormalidades, quando inseridas na narrativa jornalística, lembram o que Barbosa e Enne (2005: 72) vão conceituar de fluxo do sensacional:

As tragédias cotidianas descrevem conteúdos imemoriais, que aparecem e reaparecem periodicamente sob a forma de notícias. Mudam os personagens, não as situações. De tal forma que podemos dizer que existe uma espécie de fluxo do sensacional que permanece interpelando o popular a partir de uma narrativa que mescla ficcional com a suposição de um real presumido. São temáticas que repetem os mitos e as representações que falam de crimes e mortes violentas, de milagres, de desastres, enfim, de tudo o que foge a uma idéia de ordem presumida, instaurando a desordem e um modelo de anormalidade.

Deste modo, considerando os "sentidos de vida" e de participação social como significações elaboradas implicitamente, subjetivamente, a partir da representação da morte na cultura, é perceptível a tensão existente na inscrição do suicídio na narrativa jornalística. Como parte de um discurso que se formula na cultura e a ela também possibilita reformulações, os meios aparecem como elemento importante pois "interferem no status quo e recriam modos de vida, porque lêem e provocam releituras de experiências subjetivas e, vale dizer, de forma às vezes tão imperativa que se tornam o lugar de onde as pessoas retiram o que sabem e o que se dispõem a compreender acerca do cotidiano e da vida" (RESENDE, 2006: 161). Da onde se infere que o processo que abrange a construção, a circulação e a recepção da narrativa jornalística sobre o suicídio em Macapá, traz no seu cerne as marcas desta intersubjetividade, como daquela própria cultura.

\section{Matrizes culturais: o dramático, o realismo grotesco e o gótico}

Para que possamos compreender as apropriações e significações atribuídas ao suicídio na imprensa amapaense, torna-se fundamental refletirmos acerca das matrizes culturais que constituem esta circularidade cultural. "Se acreditamos que tal objeto só pode ser entendido

\footnotetext{
${ }^{13}$ É importante citar que a "loucura" entre estas categorias da "anormalidade" atribuídas ao suicídio aqui são as que se constroem socialmente como representações da cultura que "explicam" o desvio do sujeito suicida ao abdicar da vida. Não se refere, portanto, às diversas construções científicas que são debatidas do âmbito da saúde mental, especialmente na psicologia e psiquiatria. Para saber mais destes estudos em âmbito nacional, ver CASSORLA, Roosevelt M. S. Do Suicídio: Estudos Brasileiros.Campinas: Papirus.1991.
} 
como processo, queremos investigar sua formação a partir dessas e de outras matrizes, para posteriormente tentar perceber suas reapropriações e usos dentro de outros cenários e demandas culturais" (ENNE, 2007: 7)

Martín-Barbero identifica na literatura de cordel os primeiros traços daquilo que viria a ser, posteriormente, o jornalismo sensacionalista. São os relatos de crimes que vão inaugurar a escrita em prosa no cordel. Através da narração do acontecimento, o detalhe e a busca das causas do fato dão o tom destes relatos que "depõem também sobre a obsessão do popular pelos crimes" (MARTÍN-BARBERO, 2006: 156).

Para o autor, é importante observar o sensacionalismo como dispositivo de interpelação do popular, sendo, portanto, muito além de um "recurso burguês" de manipulação e alienação, ou apenas com propósitos mercadológicos:

O sensacionalismo delineia então a questão dos rastros, das marcas deixadas no discurso da imprensa por uma outra matriz cultural, simbólico-dramática, a partir da qual são modeladas várias práticas e formas da cultura popular. Uma matriz que não opera por conceitos e generalizações, mas sim por imagens e situações; excluída do mundo da educação oficial e da política séria, ela sobrevive no mundo da indústria cultural, onde permanece como um poderoso dispositivo de interpelação do popular. (MARTIN-BARBERO, 2006: 250)

Sendo uma operação que se dá a parte da "educação oficial" (ou do padrão hegemônico), é perceptível a pertinência da observação da inscrição do suicídio na narrativa jornalística enquanto transgressão de um tabu, ao explorar o inominável, utilizando, para isto, narrativas referentes à noção de popular.

A singularidade e a personalização dos casos, evidenciados nos atos suicidas transformados em pauta jornalística, remontam a uma matriz cultural que está associada aos jornais auto-intitulados populares, como se pode observar no trecho abaixo:

De acordo com o depoimento de sua amásia, Cristiane da Cruz Coelho, 20 anos, Klépis teria suicidado por causa da cobrança de várias dívidas contraídas. Ela disse que hoje pela manhã, ele acordou cedo, como de costume, para abrir o comércio que tinha em frente à sua casa. Depois de beijá-la, ele dirigiu-se ao banheiro. "Foi quando eu escutei o tiro" conta Cristiane, em meio a soluços. Quando ela entrou no banheiro, encontrou-o sentado no chão, ensangüentado ${ }^{14}$.

\footnotetext{
14 Trecho da matéria intitulada "Mais um suicídio aumenta a infeliz estatística no Amapá", publicada no periódico A Gazeta, em 15.06.2004.
} 
Deste modo, percebe-se, a partir desta matriz popular, que são valorizados nestes periódicos o cotidiano, a fruição individual, o sentimento e a subjetividade:

Os assuntos públicos muitas vezes são ignorados, o mundo é percebido de maneira personalizada e os fatos são singularizados ao extremo. O enfoque sobre os grandes temas recai sobre o ângulo subjetivo e pessoal. O público leitor, distante das esferas de poder, prefere ver sua cotidianidade impressa no jornal e a informação é sinônimo de sensação e da versão espetacularizada das diferentes realidades individuais (AMARAL, 2005: 8).

Esta valorização da cotidianidade e da subjetividade no jornalismo popular/sensacionalista, por sua vez, apresenta-se como contraponto à racionalidade e a objetividade propostas no jornalismo de referência, argumentos que retiram os fatos que transgridem a ordem social, como o suicídio, de suas pautas.

Para melhor perceber os fluxos, articulações e tensionamentos que compõem a construção das narrativas sobre suicídio, considero relevante destacar três matrizes culturais que são evidenciadas em estudos sobre o sensacionalismo: a matriz dramática, o realismo grotesco e o gótico, associado ao horror. É pertinente, portanto, considerá-las em relação, sendo reapropriadas e adaptadas ao tratar da morte voluntária no espaço da imprensa amapaense.

A matriz dramática está diretamente associada à narração enquanto forma de desenvolvimento do texto que, não raro, apresenta os fatos ao leitor mantendo uma relação interpessoal. A retrospectiva da vida do suicida e a descrição da cena da morte são recursos que ativam sentimentos como dor, medo ou pesar:

O corpo dele foi encontrado por volta das $14 \mathrm{~h}$ depois que parentes, desconfiados com o silêncio no interior da casa, arrombaram a porta do imóvel. Foi neste momento que a esposa de Roberto o viu com uma corda no pescoço. "Quando a gente chegou, o coração dele ainda estava batendo", conta a esposa do ex-policial, que acionou o corpo de bombeiros em seguida. [...] De acordo com informações de parentes de Roberto, ele estava sob liberdade condicional desde 2001. [...] Após cumprir 1/3 da pena, o expolicial conseguiu uma condicional, na quarta-feira da semana passada. Ele alugou a casa onde fora encontrado morto e foi morar com a sua esposa e três filhos.

Pela manhã, ele recebeu um documento da vara de Execuções Penais avisando que às $18 \mathrm{~h}$ seria recolhido novamente ao Complexo Penitenciário. Ele havia dito a uma colega de trabalho que não agüentaria voltar para penitenciária. [...] deixou um bilhete pedindo a colega de trabalho que caso 
fizesse "alguma besteira", era para ela dizer a família dele que não deixassem de ajudar a sua esposa e os três filhos ${ }^{15}$.

A esquematização e polarização maniqueísta (MARTIN-BARBERO, 2006: 168-169), que na estrutura melodramática divide os personagens entre bons e maus, traidores e vítimas, são exemplos constantes nas narrativas aqui citadas, em que o suicida (normalmente protagonista) oscila entre os dois pólos, devido à complexidade em que se inscrevem tais tramas.

O realismo grotesco poderia ser relacionado especialmente às imagens presentes nas notícias sobre suicídio. São fotografias que exibem o corpo e valorizam os detalhes da cena, particularizando o suicida. No caso do estudo que exemplifica este ensaio, no período de dois anos foram publicadas 36 matérias sobre o tema. Destas, 13 continham fotos e 11 foram destaque na capa. Dentre as matérias com fotografia, nove apresentavam o corpo do suicida e o restante ilustrava o cenário da morte. Neste aspecto, é possível retomar a proposta elaborada por Martín-Barbero (idem: 102) que relaciona o realismo grotesco a "um mundo em que o corpo ainda não foi separado e fechado [...] o realismo do corpo" - o que nos remete à materialidade do corpo, aproximando-o da degradação do humano pela morte voluntária.

Por fim, destaco enquanto matriz para pensar o suicídio o gótico: "diretamente relacionado ao ethos romântico, entendido como resistência à negação do sentimento e das emoções por parte do racionalismo burguês" (BADDELEY apud ENNE, 2007: 7). O suicídio, desta feita, é representado nas notícias como ato extremo cujas motivações do sujeito são exploradas na narrativa - tendendo, quase sempre, a demonstrar a ausência de razão e o excesso de emoção por parte do suicida.

Uma mistura de álcool de relacionamento amoroso não correspondido levou o autônomo Rosenildo Moraes da Silva, de 27 anos, a tirar a própria vida por meio de enforcamento. [...] Seu Francisco [pai da vítima] revelou que Rosenildo ainda chegou a avisar, minutos antes de se enforcar, que cometeria suicídio. "Ele entrou em casa e me acordou 'pai, eu vou fazer um serviço comigo'. Eu não dei muita atenção porque, além de não entender muito bem o que queria dizer, ele nunca havia falado ou tentado se matar antes e por isso eu não desconfiei”, explica o pai da vítima.

[...] Ao ser questionado se desconfia dos motivos que levaram o autônomo a tirar a própria vida, seu Francisco disse que ultimamente Rosenilton enfrentava sérios problemas com bebida alcoólica e reclamava de uma paixão não correspondida, contudo, não chegou a revelar o nome da mulher. ${ }^{16}$

\footnotetext{
${ }^{15}$ Trecho da matéria intitulada "Ex-policial se mata ao saber que voltaria para o Copen", publicada no periódico A Gazeta, em 07.10.2004.

${ }^{16}$ Trecho da matéria intitulada "Homem se mata por amor", publicada no periódico A Gazeta, em 24.01.2005.
} 
A partir do gótico pode-se associar, ainda, o horror - que está relacionado a "representações acerca do outro, fazendo um jogo narrativo especular que oscila entre o medo e o desejo, e que tem como construção narrativa fundamental o monstro, o espetacular, aquele que moralmente traz o sinal de advertência acerca do mal e da perdição" (ENNE, 2007: 11).

Esta relação de alteridade, que apresenta através dos protocolos de leitura os limites do outro e os limites de si, baseia-se na lógica que constitui o fluxo do imaginário, do sensacional (idem, p. 9). Esta lógica está na representação ambivalente do suicida, que ora interpela o leitor e seus limites (mediante o confronto das duas realidades), ora apresenta-se enquanto exemplo de fragilidade perante o mal, ao desistir da própria vida.

O caminho percorrido até o momento não fecha a questão (nem seria este o propósito), mas dá pistas para se refletir sobre os sentidos adquiridos pela morte voluntária através de sua inserção na imprensa, no contexto específico do Amapá. Assim, os casos de suicídio são caracterizados como "ações sociais", o que indica ser necessário considerar os significados práticos, visíveis (como dados e registros estatísticos) e os abstratos (como as matrizes culturais) para o ato, sendo estes últimos preponderantes para descrevê-lo (DOUGLAS apud NUNES, 1998: 17).

Estes significados abstratos são constituídos através de fluxos, em que se produzem e circulam sentidos, significações, sensibilidades, representações de vida e de morte, que, por sua vez, só se observam em sua existência no cotidiano, nas próprias relações. Ou seja, inclusive e apesar das caracterizações mais amplas como lugares legitimados para observação do suicídio, é perceptível a relevância da ancoragem territorial (MARTINBARBERO, 2003: 58), na ordem das práticas sociais cotidianas, no tecido das proximidades e solidariedades, que se inscrevem as significações, para observar estas narrativas. Isso indica a importância de descrever o contexto cultural do Amapá, como forma de melhor refletir sobre o espaço da recepção destas mensagens - local onde efetivamente tais mensagens adquirem sentido.

\section{O palco da narrativa: hibridização, cultura popular e resistência}

Ao observar a cultura amapaense é importante ter em vista a proposta de MartínBarbero (2006: 218) que analisa a originalidade da cultura latino-americana a partir do sentido de descontinuidade, de modernidade não-contemporânea. Para o autor, a originalidade destes 
países foge à lógica do desenvolvimento capitalista, o que configura outra forma de conceber a ideia de "atraso" no processo de modernidade destes locais.

Deste modo, é preciso compreender tanto o que o atraso representou em termos de diferença histórica (sendo este um atraso que foi historicamente produzido), quanto é importante perceber "o que apesar do atraso existe em termos de diferença, de heterogeneidade cultural, na multiplicidade de temporalidades do índio, do negro, do branco e do tempo decorrente de sua mestiçagem" (idem, grifos meus). É necessário, portanto, observar o desenvolvimento econômico, social e cultural do Amapá como um processo historicamente construído, cujas origens não se limitam a questões externas, mas se estruturam especialmente na heterogeneidade cultural e na mestiçagem dos povos que compõem aquela sociedade.

No que diz respeito às particularidades "fundantes" da cultura amapaense, é valiosa a contribuição das tradições caboclo ribeirinhas, que conservam hábitos e modos de vida que têm uma relação fortemente ligada à natureza - referência direta à cultura amazônida. $\mathrm{Na}$ composição desta rede simbólica, tem-se a intersecção de referentes rurais e urbanos de maneira sobreposta. Não é demais lembrar, também, que a multiplicidade desta cultura tem a marca do deslocamento geográfico (que só permite o acesso via aérea ou fluvial), e a influência de um fluxo migratório ${ }^{17}$ intenso desde a transformação do território federal em estado, com a constituição de 1988. Este isolamento, aliás, permite a produção freqüente de narrativas locais que, curiosamente, registram esta noção de desconexão com o contexto nacional quando se referem ao eixo econômico e político como "lá no Brasil”.

Neste cenário, é perceptível o quanto os meios de comunicação exercem um importante papel de conexão entre "o estado" e "o país”. Esta conexão midiática, contudo, se dá através de um padrão hegemônico que opera como dispositivo paradoxal de controle das diferenças, possibilitando vínculos opostos como a familiarização e a exotização (MARTINBARBERO, 2006: 254).

As trocas de experiências e valores múltiplos, dispostos numa rede simbólica heterogênea em que interagem local, nacional e transnacional, aproximam a noção de hibridização formulada por Canclini (1997b) e inscrevem Macapá num lugar muito rico e especial para a investigação da relação entre comunicação e cultura. Ao mesmo tempo, e como reforço desta noção, são perceptíveis ali valores que designam traços fortes de

\footnotetext{
${ }^{17}$ Segundo o IBGE (2006), 25\% da população residente no Amapá é formada por pessoas não naturais daquele Estado. IBGE, Pesquisa Nacional por Amostra de Domicílios. Migração/Amapá. Disponível em (2006.ftp://ftp.ibge.gov.br/Trabalho_e_Rendimento/Pesquisa_Nacional_por_Amostra_de_Domicilios_anual/200 6/Volume_Brasil/Unidades_da_Federacao/Amapa/).
} 
resistência local, como parte da formulação de uma cultura que, embora visualize o contexto nacional de maneira muito próxima e constante, especialmente pela penetração dos meios (familiarização), não se expõe ou não é inscrito neste mesmo contexto amplo que ordena e no qual circulam as narrativas midiáticas nacionais. Como conseqüência, não é visto ou reconhecido pelo "outro", neste espaço ampliado, por suas particularidades culturais (exotização).

Neste sentido, tenho em mente a dinâmica própria do processo cultural: "a cultura popular fazendo-se em uma dialética de permanência e mudança, de resistência e intercâmbio" (MARTIN-BARBERO, 2006: 201). Ao visualizar a cultura amapaense, e, especialmente, a inscrição e a circulação das notícias sobre suicídio naquele espaço, tenho em vista uma produção jornalística que se caracteriza enquanto expressão da cultura popular. Uma narrativa midiática que apresenta resistência aos padrões consensuais ao tratar (e por isso construir significações que são apropriadas e/ou negociadas pelos receptores) de um tabu tido como inominável no restante do país, inclusive entre os demais periódicos do mesmo gênero.

Para melhor explicitar esta noção de tratar-se de uma narrativa resistente é importante relembrar que as notícias sobre suicídio, neste contexto cultural, são uma constante em todos os meios de comunicação massivos - sendo os dados estatísticos aqui apresentados referentes a um periódico, somente a título de ilustração. Entende-se, portanto, que estamos tratando de um exemplo existente em um contexto mais amplo, que relaciona a comunicação e a cultura e que, para isso, precisa ser analisado em suas especificidades.

A maneira de observar este objeto, portanto, é que pode fazer emergir uma reflexão mais aproximada da relação que dimensiona a resistência do popular nestas narrativas. Para tanto, é preciso estar atento a comum valoração do sensacionalismo a uma dimensão pejorativa do popular, a partir de "estratégias de distinção tendem a relegar o sensacionalismo à vala do mau gosto e, por conseqüência, do mau objeto reflexivo" (BORGES e ENNE, 2007: 11).

Assim, o que levanto como proposta está longe daquilo que enxerga o resistente como distante, e, por isso, estranho ou "interessante" ${ }^{18}$. O trabalho de descortinar o que se encontra

\footnotetext{
${ }^{18}$ Tomo o cuidado, neste momento, de propor que a observação (mesmo que breve) deste exemplo, não possa suscitar um referente que normalmente reforça a tendência de caracterização do diferente. Seguindo a lógica de Jesús Martín-Barbero (2003: 72), refletindo a partir de Muniz Sodré, a noção de si muitas vezes se dá num mecanismo de distanciamento, "exotiza-se o outro, folcloriza-se o outro em um movimento de afirmação da heterogeneidade que, ao mesmo tempo o torna 'interessante', o exclui de nosso universo, negando-lhe a capacidade de interpelar-nos e questionar-nos".
} 
nas narrativas resistentes cumpre-se especialmente em colocá-las em observação, sem modificá-las para isso. Para enxergar tais narrativas, portanto, é preciso considerá-las em seu contexto de significação e circulação. O que demanda conceber o estudo da cobertura amapaense sobre o suicídio como uma possibilidade de aproximar-se da significação da cultura, das práticas e participações destas narrativas da imprensa neste contexto cultural, espacial e temporalmente dado - o que, por fim, se dedica a refletir sobre as relações e formas de se pensar as realidades sociais que constroem (e se constroem com) os meios de comunicação (RESENDE, 2006: 164).

\section{Considerações finais e propostas de continuidade}

A proposta deste texto centrou-se na observação das narrativas sobre suicídio presentes na imprensa amapaense a partir do caráter processual que relaciona comunicação e cultura. Para tanto, buscou-se evidenciar a pertinência do tema através do mapeamento de dados estatísticos e da reflexão sobre o processo histórico e cultural que constitui o suicídio enquanto tabu - o que torna sua inscrição na mídia uma narrativa de resistência, que está associada com características do popular e do sensacionalismo.

Os sentidos adquiridos pela morte voluntária nesta narrativa foram refletidos através de algumas matrizes culturais que constituem o sensacionalismo: matriz dramática, o realismo grotesco e o gótico, sendo este último também associado ao horror. Deste modo, quando tratamos a ideia de resistência, temos em vista a transposição de um tabu e de uma lógica hegemônica, que sugere a economia dos sentimentos, a objetividade e, por isso, a não exposição de assuntos controversos, como o suicídio, na mídia. Esta noção de resistência do popular através do sensacionalismo é evidenciada por Martín-Barbero:

(...) somente correndo riscos se pode descobrir a conexão cultural entre a estética melodramática e os dispositivos de sobrevivência e de revanche da matriz que irriga as culturas populares. Uma estética melodramática que se atreve a violar a separação racionalista entre os assuntos sérios e os temas destituídos de valor, a tratar os fatos políticos como fatos dramáticos e a romper com a "objetividade" observando as situações a partir daquele outro ponto de vista que interpela a subjetividade dos leitores (2006: 250, grifos do autor).

A observação desta interpelação da subjetividade dos indivíduos/leitores através da narrativa midiática sobre o suicídio, na cultura amapaense, é o exercício que se propõe para a continuidade desta reflexão aqui iniciada. Isso sinaliza que, diante do que foi ponderado até este momento, a possibilidade de dar seqüência a uma investigação deste objeto se organizaria 
a partir de uma pesquisa de recepção. O que implica em observar a circulação de valores que compõem o imaginário do suicídio segundo elaboração organizada pelos sujeitos que estão inscritos naquele contexto, considerando-os frutos de significações partilhadas, inscritas na subjetividade e também no imaginário social.

Tendo em vista a reflexão até aqui elaborada, é possível inferir que o suicídio não deixa de ser inscrito enquanto tabu naquela circularidade cultural. É a sua condição de tabu, aliás, que subsidia a sua relevância enquanto tema controverso, e por isto de interesse para exposição midiática, cuja narrativa popular/sensacionalista é amplamente difundida, naquele contexto. Deste modo, não se trata da construção de "novos mapas de significado" para o suicídio, tal como questionamos inicialmente. O que fica mais evidente, neste raciocínio, são novas formas de apropriação e uso das representações sobre o suicídio, que são postas em circulação e tensionamento a partir das narrativas jornalísticas.

Esta ideia, evidentemente, é indicada aqui como uma pista, como uma possibilidade para o desenvolvimento do tema. Esta ampliação, contudo, só mantém o sentido original a partir da perspectiva que entende a morte enquanto tema que possibilita o acesso simbólico de bases culturais importantes de uma sociedade. Assim, penetrar na construção desta narrativa jornalística que trata da morte voluntária, investigando através dos seus receptores as apropriações, negociações e resistências dos sentidos ali representados, possibilitaria enxergar, por conseguinte, a cultura macapaense de forma mais aproximada

\section{Referências Bibliográficas}

AMARAL, M. F.. Sensacionalismo, um conceito errante. In Texto (UFRGS. Online), Porto Alegre, v. 13, p. 01-13, 2005.

BARBOSA, Marialva; ENNE, A. L. S.. O jornalismo popular, a construção narrativa e o fluxo do sensacional. Eco-Pós (UFRJ), v. 8, p. 4, 2006.

BERGER, Perter L.; LUCKMANN, Thomas. A construção social da realidade: tratado de sociologia do conhecimento. Petrópolis: Vozes, 1985.

BORGES, Wilson Couto; ENNE, A. L. S.. Sensacionalismo e modernidade: como uma relação intrinsicamente ambigua se transformou em estratégia de distinção cultural?. Rumores, v. 1, p. 1-14, 2007.

CAMUS, Albert. O mito de Sísifo: ensaio sobre o absurdo. Lisboa: Edições Livros do Brasil, s/d.

CANCLINI, Nestor Garcia. Cultura e comunicación: entre lo global y lo local. La Plata: Ed. De Periodismo y Comunicación, 1997a. 
. Culturas Híbridas. São Paulo: Edusp, 1997b.

DAPIEVE, Arthur. Morreu na contramão: o suicídio como notícia. Rio de Janeiro: Jorge Zahar, 2007.

ENNE, A. L. S.. O sensacionalismo como processo cultural. Eco-Pós (UFRJ), v. 10, p. 70-84, 2007.

HALL, Stuart et al. A produção social das noticias: o mugging nos media. In: TRAQUINA, Nelson (org.). Jornalismo: questões, teorias e 'estórias'. Lisboa: Vega, 1993.

MARTÍN-BARBERO, Jesús. Globalização comunicacional e transformação cultural. In: MORAES, Dennis de (org). Por uma outra comunucação - mídia, mundialização cultural e poder. Rio de Janeiro: Record, 2003, p. 57-85.

. Dos meios às mediações: comunicação, cultura e hegemonia. 4. ed. Rio de Janeiro: Editora de UFRJ, 2006.

MARTINS, José da Souza (org). A morte e os mortos na sociedade brasileira. São Paulo: Hucitec, 1983.

MORIN, Edgar. O homem e a morte. Trad. Cleone Augusto Rodrigues. Rio de Janeiro: Imago, 1997.

NUNES, Everardo Duarte. O suicídio - reavaliando um clássico da literatura sociológica do século XIX. Cad. Saúde Públ., Rio de Janeiro. 14(1): 7-34, jan-mar-1998.

RESENDE, Fernando. Jornalismo e enunciação: perspectivas para um narrador-jornalista. In: LEMOS, André; BERGER, Christa; BARBOSA, Marialva (org.). Narrativas midiáticas contemporâneas. Porto Alegre: Sulina, 2006.

SOUSA, Mauro W. Recepção e comunicação: a busca do sujeito. In: (org). Sujeito, o lado oculto do receptor. São Paulo: Brasiliense, 1994. p. 13-38.

WAISELFISZ, Julio Jacobo. Mapa da Violência IV: os jovens do Brasil. Brasília: UNESCO; Instituto Ayrton Senna, 2005. 